\title{
LA COMPETENCIA INTERCULTURAL COMO LLAVE PARA EL DESARROLLO DEL PERÚ
}

\section{THE INTERCULTURAL COMPETENCE AS A KEY ELEMENT FOR THE DEVELOPMENT OF PERU}

\author{
Sigrid Gómez-Schlaikier ${ }^{1}$
}

\section{RESUMEN}

El término «competencia intercultural» originalmente se refería a las destrezas y las actitudes conscientes que el estudiante y todos los implicados en la enseñanza de una lengua extranjera tenían que desarrollar para conocer el contexto sociocultural y decodificar los mensajes del idioma que estaban enseñando-aprendiendo, acepción que ha dejado de ser exclusiva de esta esfera. Este artículo trata de cómo la aplicación de la competencia intercultural ha adquirido gran importancia en las relaciones internacionales, la cooperación internacional, los programas educativos y los negocios, pues permite optimizar la comunicación entre distintos países y culturas. Además, reflexiona acerca de su aplicación a la realidad nacional. Finalmente y como referencia, presenta un ejemplo de lo que puede ser una buena práctica de «competencia intercultural» con la cultura china.

Palabras claves: globalización, migración, competencia intercultural, descentralización, China.

\section{ABSTRACT}

The term «intercultural competence» originally referred to the conscious skills and attitudes that the student and everyone involved in teaching a foreign language had to develop to understand the sociocultural context and decode messages from the language they were teaching-learning, meaning is no longer exclusive to this area. This article is about how the implementation of intercultural competence has become very important in international relations, international cooperation, education and business; it allows optimizing the communication between different countries and cultures. Also, focus on its application to the national situation. Finally, gives an example of what can be a good practice of «intercultural competence» with the Chinese culture as a reference.

Key words: Globalization, migration, intercultural competence, decentralization, China.

1 Miembro del Centro de Estudios Económicos y Sociológicos de la Universidad de Hamburgo, ZÖSS (Alemania). Master of Arts en Estudios Económicos y Sociológicos de la Universidad de Hamburgo (Hamburger Universität), Alemania.<sigrid.gomez@yahoo.es>. 


\section{INTRODUCCIÓN}

En este mundo globalizado, caracterizado por el incremento transnacional de economías, mercados, medios de transporte, comunicación y otros, se presentan a cada momento múltiples posibilidades de contacto con las más diversas culturas. Lamentablemente, en muchas ocasiones debido al desconocimiento o las limitaciones que tenemos en el trato con gente perteneciente a otras realidades desperdiciamos, desaprovechamos o dejamos pasar oportunidades que podrían ser enriquecedoras y de gran provecho en los aspectos humano y económico, entre otros.

En la era de la globalización tenemos la posibilidad de contactar y conocer gente con mayor facilidad; sin embargo, percibimos que nuestros conocimientos no cubren las expectativas requeridas para manejar determinadas situaciones con personas de otras realidades o culturas. De ahí la importancia de la competencia intercultural como medio fundamental para superar el déficit de «entendimiento» entre las diversas culturas, por lo que su aprendizaje actualmente es impulsado en gran número de países europeos dentro de los programas estudiantiles, la cooperación internacional, las relaciones internacionales y el ámbito empresarial.

La competencia intercultural consiste en estar capacitado, es decir, tener las actitudes, los conocimientos y las habilidades necesarios para lograr una comunicación exitosa con personas de distintas culturas internacionales o intranacionales con las que deseamos comunicarnos. Esta competencia puede ser en parte innata, pero también implica un aprendizaje, el conocimiento, el entendimiento y la destreza para tener llegada a la cultura con la cual se va a entablar contacto. Asimismo, se trata de la capacidad de comunicar nuestra propia cultura en forma clara y comprensible a nuestro interlocutor. Este artículo trata de la competencia intercultural y la importancia que se le debe otorgar por todas estas razones.

\section{LA COMPETENCIA INTERCULTURAL}

De acuerdo con las definiciones del diccionario de la Real Academia Española, «competencia intercultural», significa poseer pericia, aptitud, idoneidad para hacer algo o intervenir en un asunto determinado «entre», «en medio», «entre varios» conjuntos de modos de vida y costumbres, conocimientos y grados de desarroIlo artístico, científico, industrial, en una época o grupo social específicos. También se entiende como el conjunto de las manifestaciones en que se expresa la vida tradicional de un pueblo.

En la era de la globalización, la competencia intercultural es una habilidad que podemos desarrollar e incrementar con el aprendizaje. Esta nos brinda las herramientas para comprender y sentirnos bien con otras culturas. Es un requisito básico, una de las reglas de juego para salir airoso en este mundo globalizado.

La competencia intercultural también puede tener otras acepciones. Por ejemplo, Santos Velasco (citado por Franco, Ilvento, Renta y Segón, 2008) prefiere utilizar la denominación «competencia comunicativa intercultural»; mientras otros autores se refieren a intercultural awareness o intercultural management.

La competencia intercultural no es fusionar, asimilar, o un proceso de inclusión de otras culturas, sino romper los mitos y los preconceptos que se tienen sobre estas. Es reconocer y aprender que existen otras realidades diferentes de la nuestra y que podemos llegar a ellas si las entendemos, sabemos tratarlas, respetarlas, tolerarlas y aceptarlas como son. Se debe tener en cuenta que los códigos y los criterios de interpretación entre una y otra cultura no son los mismos y, por tanto, se requiere de un amplio criterio para manejar situaciones inesperadas que podrían interferir en la comunicación.

«La competencia intercultural es un atributo transversal, valorable y útil a todas las personas que trabajan y se relacionan con personas de otras culturas $y$, por lo tanto, posible recurso para el ejercicio de la ciudadanía o medio para el logro de la misma» (Aneas, 2005: 1). El grado de visión, conocimiento, aceptación, tolerancia y comprensión que favorezca una relación más armoniosa y tolerante con otra cultura va a medir nuestra competencia intercultural.

El gráfico y los cuadros siguientes dan cuenta de las diversas aproximaciones conceptuales al tema. 


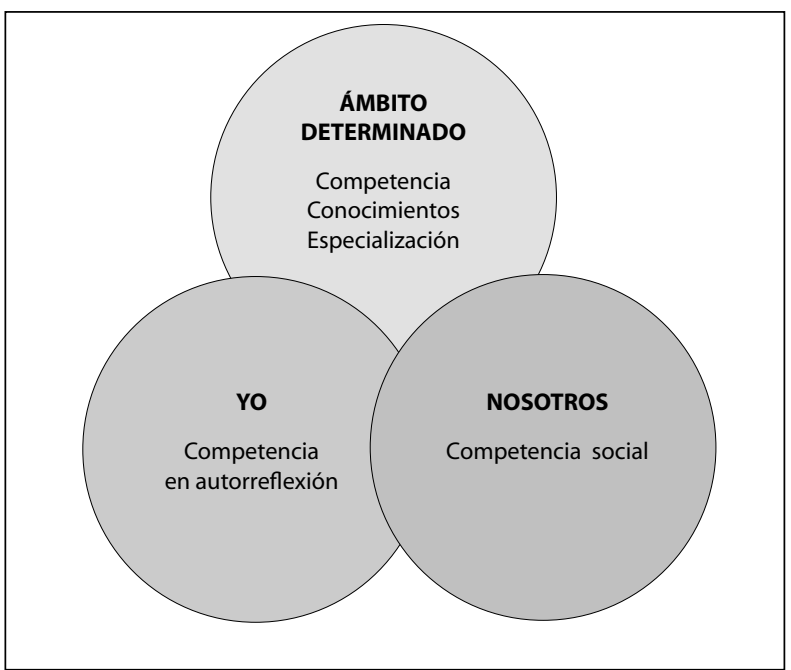

Tomado de: Fischer, 2003. Traducción de la autora.

Gráfico 1

La competencia intercultural según Fischer, 2003

Cuadro 1. La comunicación intercultural según Santos Velasco, 2004, y Stone, 2006

\begin{tabular}{ccc}
\hline Modelos & $\begin{array}{c}\text { Competencia comunicativa intercultural } \\
\text { Santos Velasco, 2004 }\end{array}$ & $\begin{array}{c}\text { Efectividad comunicativa intercultural } \\
\text { Stone, 2006 }\end{array}$ \\
\hline Elemento & Ámbito & Ámbito \\
\hline Competencia intercultural & Comportamental & Habilidades (skills) \\
\hline Sensibilidad intercultural & Afectivo & Afectivo (emotional) \\
\hline Conciencia intercultural & Cognitivo & Conocimiento (knowledge) \\
\hline
\end{tabular}

Tomado de: Franco, Ilvento, Renta y Segón, 2008.

Cuadro 2. Competencia intercultural en orientación según Pedersen, 1994

\section{Desarrollo de la autoconciencia (awareness)}

Analizar los sentimientos, las actitudes y las creencias propios hacia personas de culturas diversas. Supone además el desarrollo de actitudes, opiniones y concepciones apropiadas sobre la interculturalidad y el modo de evitar prejuicios y estereotipos que entorpezcan la relación orientadora.

\section{Desarrollo de conocimientos}

Obtención de nociones concretas e información clara acerca de los conceptos de cultura e interculturalidad y sobre los colectivos culturales con los que se ha de intervenir.

\section{Desarrollo de destrezas}

Pretende capacitar al orientador para intervenir con personas y grupos de diversa procedencia, mediante las técnicas y las estrategias adecuadas.

Tomado de: Malik, s. f. 


\section{MIGRACIÓN Y COMPETENCIA INTERCULTURAL}

La migración en todas sus variantes es una característica de esta época. Para definir y analizar los diferentes tipos de migración se pueden tener en cuenta diversos aspectos. Así, si se considera el espacio se puede diferenciar entre migración interna o externa.También se puede distinguir entre migración voluntaria o forzada. Si se toma en cuenta el factor tiempo, la migración puede ser temporal o permanente. Asimismo, se puede clasificar de acuerdo con su motivación; por ejemplo, por negocios, estudios, turismo, etcétera.

En esta época, la migración ya no se puede tratar aisladamente, pues es una de las características más notorias de una sociedad globalizada, que debe ser vista y tratada en un contexto tanto socioeconómico como cultural.

Es sabido que los países industrializados son muy atractivos y ofrecen un amplio mercado laboral para los migrantes, mientras que los países de origen, debido a sus problemas políticos, falta de perspectivas y posibilidades de desarrollo, impulsan a su población a la migración. También se da el caso de empresas de países industrializados que prefieren trasladar su producción a países donde obtienen mejores beneficios y pueden incrementar sus capitales de modo sustancial.

Todos estos fenómenos confirman los pronósticos sobre que las tendencias migratorias afectarán cada vez a más países; lo que significa que habrá mayor diversidad de países de origen y de destino involucrados en el proceso migratorio internacional $y$, por tanto, se incrementarán tanto el desplazamiento de culturas como la convivencia entre estas en territorios ajenos a los propios.

Las características que definen la competencia intercultural son factores determinantes para una coexistencia en armonía en países y sociedades multiculturales o con personas de otras culturas. Esto significa que en los procesos migratorios la competencia intercultural va a determinar el grado de armonía de la convivencia con culturas ajenas a la propia. Así, gran parte de los migrantes puede obtener mejores ingresos gracias a su competencia intercultural. Es un hecho conocido que el latino goza de gran aceptación por su capacidad de adaptación a culturas ajenas a la propia.

De acuerdo con investigaciones propias entre diferentes grupos de latinos en Alemania, pude determinar el gran desarrollo de la capacidad intercultural que estos alcanzan. En su mayor parte eran personas de diferentes nacionalidades que compartían pequeños espacios de vivienda y donde la coexistencia por lo general era armónica. Si bien no había ausencia de problemas, estos habían sido traídos con la migración: la mayoría estaba en situación de estadía irregular y tenía que pasar desapercibida (inclusive los niños) en la sociedad alemana. Sin embargo, los ideales que traían y los beneficios que obtenían estos migrantes hacían la convivencia más llevadera. Esta necesidad los motivaba a desarrollar actitudes y destrezas interculturales que marcaban la diferencia entre su permanencia y la deportación del país.

Se debe ser consciente de que el manejo de ciertos conocimientos, la capacidad de aprendizaje, la aceptación, la actitud y el respeto en sociedades multiculturales como la nuestra es mínima y que todas estas capacidades deben incrementarse y desarrollarse. Nuestra realidad relega el tema de la interculturalidad cuando se refiere a nuestro país y, por el contrario, lo considera respecto de lo extranjero.

Cada día llegan más migrantes al Perú, extranjeros quienes, por uno u otro interés, son competentes interculturalmente para entenderse con diferentes grupos culturales locales. Estos grupos, a su vez, suelen tener mayor y mejor comunicación con extranjeros capaces de comprender y respetar sus culturas que con sus propios connacionales.

Como escribiera Castells: «... el Estado tiene que fortalecer las identidades nacionales que pueden ser absorbidas como resultado de los procesos de globalización» (Castells, 2003: 235). Pero no solo se trata de fortalecer las identidades nacionales sino de aprender a valorarlas y tener la competencia intercultural para interactuar indistintamente entre ellas. Tenemos que ser un Estado fuerte y soberano, los grandes capitales transnacionales y las importantes olas migratorias no deben ser más firmes que nuestra unión para sacar 
adelante nuestro país. Tenemos que estar dispuestos a apostar por la competencia intercultural intranacional.

\section{IMPORTANCIA DEL DESARROLLO DE LAS CAPACIDADES INTERCULTURALES Y EL RIESGO DE IGNORARLAS}

Este acápite se ocupa del desarrollo de capacidades interculturales y las consecuencias de su descuido en distintos ámbitos: la cooperación internacional, la política exterior, los programas de educación y los negocios, entre otros,

\section{La competencia intercultural en la cooperación internacional}

Con el paso del tiempo, los países industrializados reconocieron que era necesario aportar diversos tipos de ayuda para subsanar, de alguna manera, las carencias que generaban tanta desigualdad con otros países, el resultado de esta iniciativa fue la cooperación internacional. El fin principal de los cooperantes era prestar ayuda y realizar proyectos a favor del desarrollo en diferentes regiones del mundo, lo que a su vez influía indirectamente en mantener mejores relaciones diplomáticas y comerciales entre los países involucrados. Con el tiempo se determinó que para lograr un mejor entendimiento y mantener las relaciones entre países en un nivel óptimo era necesario que los llamados cooperantes, conocedores no solo del idioma, la historia, la geografía y otras características de los países de destino, desarrollaran también destrezas interculturales para tener estrategias de intervención más adecuadas. Todo esto significaba una mayor llegada a sociedades de diferentes costumbres, culturas y etnias en los países de destino, para conseguir sus metas de manera más eficaz.

En la actualidad, antes de enviarlos al extranjero, muchos países preparan a sus cooperante, quienes deben aprender mecanismos para lograr una mejor comunicación dentro de un medio distinto del suyo. En consecuencia, la capacidad que se desarrolle será la que determine el grado de competencia intercultural que tenga cada persona para lograr un entendimiento eficaz entre ambas partes.
Si bien el manejo de la competencia intercultural de parte de la cooperación internacional resulta beneficioso para un mejor desenvolvimiento de los cooperantes, conlleva también la creación de espacios a los que muchas veces no tienen acceso los nacionales. Lo que se suele apreciar igualmente en muchas ONG extranjeras. Esta realidad debe obligarnos a tener una actitud respecto de la importancia de otras culturas y realidades nacionales; de lo contrario, seguiremos cediendo espacios de diversa índole en nuestro propio territorio debido a nuestra falta de tolerancia, visión y competencia intercultural.

\section{La competencia intercultural en la política exterior y el proceso de descentralización nacional}

Tan solo por nombrar algunos ejemplos: estados, transacciones económicas, políticas migratorias, tratados comerciales y otros similares están relacionados y actúan en forma interdependiente; por ello, en el mundo globalizado en que vivimos la política exterior desempeña un papel de extrema responsabilidad.

En la década de 1990, el gobierno alemán creó una escuela de formación para diplomáticos de todas partes del mundo cuyos lemas son «El uno con el otro», «Uno para el otro»y «Mundialmente». Estos cursos se dictan en inglés o alemán para diplomáticos de aproximadamente cien países. En ellos se aprende o profundiza en temas relacionados con la política exterior, los principios de integración y la posición de Alemania y Europa. De esta manera se logra que los participantes se interrelacionen y se pueda llegar, en un futuro, a una política exterior basada en acuerdos conjuntos. El programa también cuenta con cursos prácticos donde el desafío consiste en tomar decisiones responsables en conjunto, aprovechando en forma interactiva el potencial de las diferentes culturas o regiones. Así, bajo el lema de Partners for Global Governance, los global players buscan opciones conjuntas para tratar temas tales como multilateralismo y economía mundial, entre otros.

En el caso de Estados Unidos, La Porte (2006) refiere que, desde hace algunos años, el Departamento de Estado está integrando de manera paralela las estrategias de la diplomacia pública y otras dedicadas a la 
diplomacia cultural. En esta última, comprendida entre las acciones diplomáticas de largo plazo, se reconoce el valor de otras culturas, la importancia de escuchar a otros y el deseo de aprender y aplicar programas que faciliten la comunicación en ambas direcciones.

Se postula que este es un factor relevante para la imagen de una nación o un líder político en el exterior y para la capacidad de persuasión de un Estado sobre la bondad de sus objetivos. Por ende, para lograrlo la competencia intercultural es indispensable. Asimismo, la sostenibilidad de las metas alcanzadas radica en ser consecuente en la diplomacia y las relaciones internacionales, pues las medidas propuestas dentro de un contexto intercultural carecerán de eficacia y correrán el riesgo de ser revertidas si no están respaldadas por hechos que demuestren la autenticidad de sus propósitos y una modificación de sus políticas.

En el Perú, la descentralización y la regionalización son parte de los procesos de reforma y modernización del Estado. En la «Evaluación del proceso de descentralización», presentada en julio de 2008 al Congreso de la República, se expusieron sus logros y limitaciones. En el informe se lee, por ejemplo:a) se requiere perfeccionar las reglas del sistema democrático en los ámbitos regional y local; b) revisar la organización del gobierno en el ámbito local para garantizar la presencia efectiva del Estado en todo el territorio nacional; y c) mejorar el esquema de articulación intergubernamental con el fin de procurar una acción coordinada en el marco del Estado unitario. Sin embargo, hace falta mucho más, como afirma Villoro:

Un Estado plural supone tanto el derecho a la igualdad, como el derecho a la diferencia. Igualdad no es uniformidad: igualdad es la capacidad de los individuos y grupos de elegir y realizar su plan de vida de acuerdo a sus propios valores, por diferentes que estos sean. El reconocimiento del derecho a la diferencia de pueblos y minorías no es más que un elemento de un movimiento más general que favorece la creación de espacios sociales en los que todos los grupos y comunidades puedan elegir sus formas de vida, en el interior del espacio unitario del Estado (citado por Tubino, 2008: 191).

Asimismo, Tubino considera que es momento de plantear la necesidad de «interculturalizar el multiculturalismo», tanto desde el punto de vista conceptual como político: «... las políticas interculturales deben ser por ello políticas de descentralización y descongestión del poder político y de fortalecimiento de la sociedad civil frente al Estado». Asimismo, opina: «... la construcción de autonomías locales es por ello la columna vertebral de un Estado plural. Pero las autonomías no deben significar el desmembramiento del Estado nacional y que cada estado deba buscar su propio modelo a seguir» (Tubino, 2008: 181).

Si bien existen propuestas para un mejor manejo de los temas referidos a la descentralización, hay que reconocer que muy poca gente posee la competencia intercultural necesaria para abordarlos. Al Perú con sus 25 gobiernos regionales, 1246 autoridades municipales y numerosas culturas y regiones naturales le queda aún un largo y difícil camino por recorrer. Quizá la opción más viable para comenzar con una nueva perspectiva de cambio sería la inserción en el plan de estudios de la educación nacional de temas relacionados con el desarrollo y la adquisición de competencias interculturales adecuadas a nuestra realidad. En este sentido es importante la perspectiva de Castells:

\begin{abstract}
El control del Estado sobre el espacio y el tiempo se ve superado cada vez más en esta era de la globalización por los capitales, bienes, servicios, tecnología, comunicación y poder que traspasan cualquier frontera. El Estado tiene que fortalecer las identidades nacionales que pueden ser confundidas o absorbidas como resultado de los procesos de globalización. El intento del Estado de reafirmar su poder en el ámbito nacional y su esfuerzo por restaurar la legitimidad, descentralizando el poder administrativo regional y local, refuerza la intención de las tendencias de acercar a los ciudadanos al gobierno (Castells, 2003: 336).
\end{abstract}

ESAN y otras organizaciones de prestigio están realizando una gran labor al capacitar a los gobiernos regionales y locales en programas de descentralización administrativa; sin embargo, sigue existiendo un gran vacío en el aspecto cultural ${ }^{1}$. El entendimiento y la di-

1. Nuevamente deseo dejar en claro que no es mi intención profundizar el concepto de cultura desde un punto de vista antropológico, etnológico ni sociológico. Cuando me refiero a cultura es en el sentido de las definiciones del diccionario de la Real Academia Española, es decir, el conjunto de las manifestaciones en las cuales se expresa la vida tradicional de un pueblo. Conjunto de modos de vida y costumbres, conocimientos y grado de desarrollo artístico, científico, industrial, en una época, grupo social, etcétera. 
fusión de la cultura de las diferentes regiones o localidades nos darían la capacidad de entendernos mejor y lograr un mayor acercamiento con las personas de otras costumbres e idiosincrasia de las diferentes regiones del Perú.

Castells (2003) se refiere al nuevo poder que reside en los códigos de información y las imágenes de representación en torno a los cuales las sociedades organizan sus instituciones y la gente construye sus vidas y decide su conducta. Afirma que este poder reside en la mente de la gente. Es necesario abandonar los preconceptos que marginan lo que nos rodea y nos quitan la oportunidad de conocernos unos a otros en nuestra auténtica dimensión. Tenemos un arduo trabajo por delante: debemos cambiar de actitud.

Muchos factores que influyeron en diversos momentos de nuestra historia dificultaron o nos alejaron de compenetrarnos y unirnos en diversos aspectos. Aquellas oportunidades históricas ya son parte del pasado, pero nuestra sociedad es multicultural, tenemos todo un futuro por delante y no debemos permitir que nada rompa la unidad de nuestro Estado-nación, es decir, del Perú. Pero, ¿cómo construir un Estado-nación en un país con tantas y tan variadas culturas y costumbres? ¿Cómo tener la capacidad de hacernos fuertes si nos conocemos tan poco y desconocemos en qué consiste nuestra fuerza?

Si la competencia intercultural es necesaria para el mejor desempeño en un mundo globalizado, ¿por qué no se puede aplicar el mismo concepto a la realidad nacional? Se trataría, entonces, del desarrollo de una «competencia intercultural nacional», o «subnacional» 0 «intranacional».

Tenemos elementos históricos, culturales, étnicos y otros en común que nos unen; pero existen también factores equivalentes que nos alejan. El tiempo perdido ya no se puede recuperar, pero podemos añadir nuevos matices a los procesos de regionalización y descentralización. La competencia intercultural es un aprendizaje. Es conocer la otra cultura, respetarla, comprenderla, saber tratarla, sentirnos bien y en armonía con la otra parte. ¡Qué mejor que sentirnos así entre peruanos!
De esta manera, la «competencia cultural intranacional» puede ser la herramienta que nos dé la posibilidad de comunicarnos y unirnos ante un mundo globalizado. Seamos conscientes del gran potencial humano y las riquezas naturales que tenemos. Debemos aprender a respetar y ser tolerantes. Todos estamos en la capacidad de desarrollar esta habilidad, pero para ello debemos estar más informados acerca de quiénes somos los peruanos.

\section{La competencia intercultural en la educación}

La Unión Europea (UE) ha hecho posible que ya no existan barreras para desplazarse entre sus países miembros; lo que ha dado lugar, en corto tiempo, a procesos migratorios a países con culturas e idiomas diferentes. El proceso de integración europea está en marcha, lo que significa que hay grandes diferencias culturales con las que se tiene que convivir. En ese contexto, la capacidad que tenga o desarrolle la gente para convivir con otras culturas será decisiva para el futuro.

Una de las principales barreras para la integración de los países de la UE es el idioma. En el caso concreto de Alemania, la educación escolar está promoviendo la enseñanza especializada del idioma, las tradiciones y la cultura alemanes a los hijos de los inmigrantes con la finalidad de promover la competencia intercultural en las instituciones de educación bilingüe, donde los hijos de los migrantes adquieren su primer contacto con el país de acogida. En el caso de los niños, el correcto aprendizaje del idioma va a ser determinante para su integración en la sociedad alemana y su futuro estudiantil o laboral.

En el nivel de la educación superior, ya desde 1987 se empezó con un programa de movilización de estudiantes y catedráticos entre algunos países de la UE y otros países europeos: el programa Sócrates. En el año 2006 este programa cambió de nombre por Erasmus (European Region Action Scheme for the Mobility of University Students). En la actualidad, este programa incluye no solo el desplazamiento de estudiantes universitarios, sino también de aprendices de oficios. Entre los años 2006 y 2007 participaron en este programa aproximadamente 160 mil estudiantes. El propósito de estos programas es desarrollar la competencia inter- 
cultural entre sus participantes. Lo que se quiere lograr es que las diferentes culturas de los países miembros de la UE adquieran competencias interculturales para interactuar mejor en distintos campos como el laboral y de investigación, entre otros.

Respecto de este tema, en el Perú se requeriría de todo un tratado. Tan solo quiero transcribir algunos testimonios que demuestran el gran déficit que la educación peruana tiene en los lugares más lejanos de nuestra patria. Este es un testimonio de un campesino quechua de mediados de la década de 1970:

\begin{abstract}
Porque somos quechuas, porque hablamos nuestra lengua y vivimos de acuerdo a nuestras costumbres y no sabemos leer y escribir, vivimos en el mundo de la noche. No tenemos ojos y somos desvalidos como los ciegos. En cambio, quienes saben leer y escribir viven en el mundo del día, tienen ojos. No tiene sentido quedarse en el mundo de la noche, porque debemos progresar para ser como los que van a la escuela y tienen ojos. Yendo a la escuela abrimos los ojos, despertamos (Montoya, citado por García, 2008: 135).
\end{abstract}

Es conveniente recordar que en 1969 ocurrió el proceso de reforma agraria y que las décadas de 1970 y 1980 son épocas de intensas migraciones internas. Estas migraciones llevaron a grandes cambios socioeconómicos y culturales para los migrantes y las sociedades de acogida. Realidad indiscutiblemente palpable en la actualidad.

Años más tarde, en 1998, se cita esta declaración: «Si mi hijo pierde su cultura sería porque quiere. Y nunca la perderá, aunque prefiera esconderla. Pero solo para sobrevivir. Es nuestro derecho como peruanos» (García, 2008: 145). Considero que si bien en un principio los migrantes preferían asumir costumbres citadinas, esto ha variado notablemente. Basados en su constancia y esfuerzo, se han ganado en corto tiempo espacios inimaginables hasta hace algunos años.

Finalmente, tenemos esta afirmación: «No es que la educación borre nuestra identidad; lo que borra, en parte, es la identidad que nos han dado los que no son como nosotros» (García, 2008: 145). Como sostiene García, estas voces revelan un conocimiento profundo de la estructura en torno al debate de la educación. También sugieren que su propia identidad (quechua, indígena, campesina) es más compleja y quizá menos frágil de lo que sugieren los activistas en la actualidad. En principio, no creo en la fragilidad de nuestra cultura. Estoy convencida de la gran capacidad y el potencial que tenemos, pero es lamentable que por diversos factores el mejor postor no seamos los propios peruanos.

El sistema educativo tiene que considerar las grandes diferencias existentes en este país multicultural. El profesorado de las zonas alejadas y menos privilegiadas del país posee una capacidad intercultural que indiscutiblemente debe ser apreciada y valorada en toda su dimensión. En los criterios de evaluación de los profesores debería también incluirse la capacidad intercultural de estos en los diferentes medios socioeconómicos, culturales y geográficos del país. La actitud, el conocimiento y la capacidad de llegada que los profesores tienen para comunicarse con sus alumnos es determinante para la formación de estos.

¿Por qué no podemos incluir en nuestro aprendizaje, aparte de la Historia del Perú, contenidos acerca de la diversidad cultural nacional? Es de admirar que los migrantes de los lugares más lejanos del país hayan «conquistado» la capital. Son ellos los que han desarrollado competencias interculturales para salir adelante en un mundo que les era «desconocido».

Quizá la competencia intercultural sea un nuevo reto de la educación en un país tan multicultural como el nuestro. Al margen del desarrollo que se alcanza en un nivel personal, se debe comenzar con la competencia intercultural en el plano institucional, para luego ir ampliándola al plano social y, finalmente, al global. Sin embargo, en el Perú estamos más preocupados por el plano global, olvidándonos del capital humano que tenemos en casa y que en poco tiempo deberá estar preparado para asumir los retos de tratados comerciales propios de una economía competitiva en un mundo globalizado, pues se corre el riesgo de ser absorbidos por culturas extranjeras dentro de nuestro territorio.

\section{La competencia intercultural en los negocios}

La palabra globalization aparece por primera vez en 1961 en un diccionario de habla inglesa. Este término, hoy generalizado dentro de diversos contextos, 


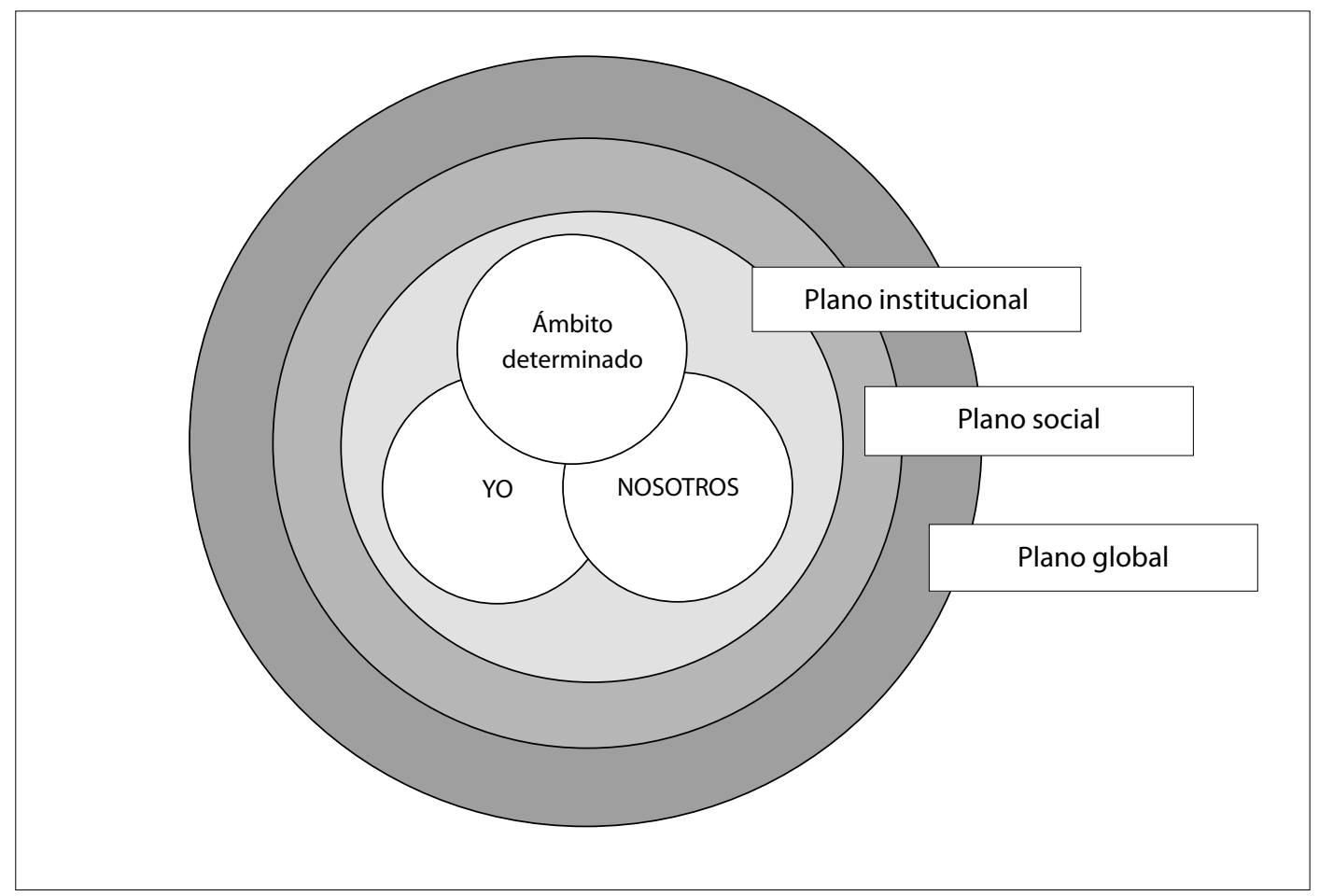

Tomado de: Fischer, 2003. Traducción de la autora.

Gráfico 2

Niveles de competencia intercultural según Fischer, 2003

fue empleado con matices económicos y políticos por Theodore Levitt (1925-2006), emigrante alemán y profesor en la Harvard Business School de Estados Unidos, en el artículo The Globalization of Markets, publicado en la Harvard Business Review (1983: 92), refiriéndose a la tendencia de los mercados y las empresas a extenderse y alcanzar una dimensión mundial.

En la actualidad vivimos la era de la globalización, caracterizada por la expansión de las economías y los mercados, los medios de transporte y de comunicación. Esta tendencia sobrepasa las fronteras nacionales. A su vez, la migración en sus diferentes variantes trae, con la movilidad intranacional e internacional, el desplazamiento cultural.

Este fenómeno genera cambios vertiginosos de los cuales somos motor y fin. Los empresarios deben estar preparados para enfrentarlos. Idiomas, actitudes, conocimientos y habilidades o destrezas les pueden ser de gran utilidad para saber contactar y comunicarse adecuadamente con personas pertenecientes a otras culturas. En un mundo de negocios globalizado la dimensión del tiempo y el espacio es muy particular. La variedad y la cantidad de oportunidades que se presentan es inmensa y el tiempo para concretar un negocio es generalmente corto.

La necesidad de poder comunicarse con nuevos mercados internacionales y cubrir el déficit de conocimientos respecto de otras culturas dio lugar a la creación de escuelas para la enseñanza, el desarrollo y el entrenamiento en competencias interculturales. En ellas los alumnos aprenden a reflexionar sobre las diferentes dimensiones interculturales: la importancia del idioma, la historia, los valores y las creencias propias y de la otra cultura. Se realizan simulaciones y juegos de roles que preparan al alumno para desenvolverse y comunicarse en situaciones interculturales, desarrollar habilidades para dar solución a problemas 
Cuadro 3. Factores, dimensiones y criterios externos que influyen en el entrenamiento intercultural

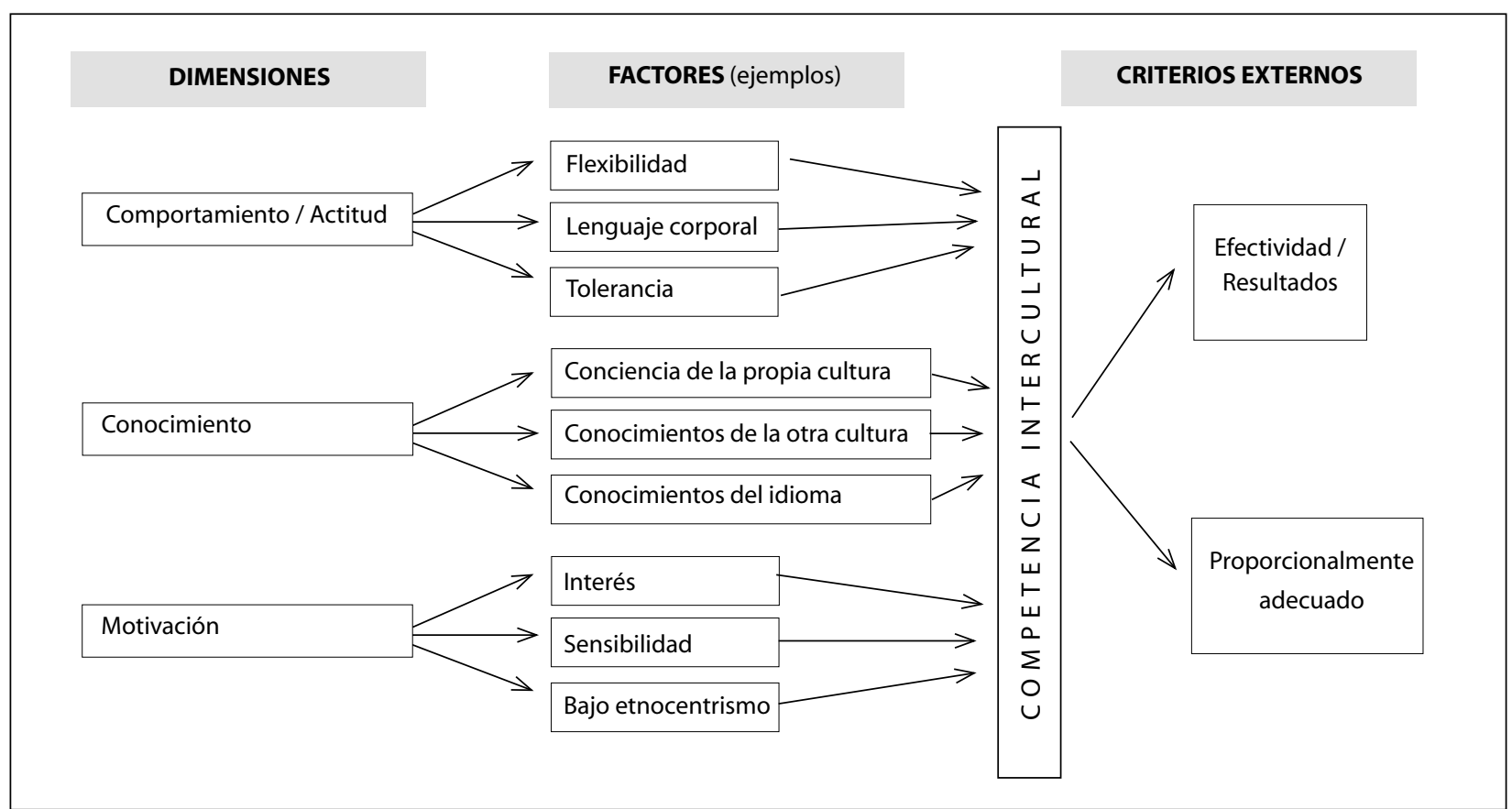

Tomado de: Zülch, 2004: 23.

Traducción de la autora.

interculturales y conocer las costumbres, las reglas de cortesía y los modelos de negociación.

La demanda de estas escuelas es cada día mayor, pues los gerentes de mayor nivel piensan que asistir a estos cursos o sesiones de entrenamiento contribuye a que las negociaciones tengan más éxito. Además, los consideran indispensables porque indican respeto hacia la otra parte a la hora de negociar.

\section{CHINA EN EL PERÚ Y EN UN MUNDO GLOBALIZADO}

La orientación de China hacia los mercados internacionales y su alto grado de expansión han dado lugar a su propia dinámica, la cual promete ser sostenible en el largo plazo. En la década de 1980 y comienzos de la década de 1990 sus tasas de crecimiento habían disminuido un poco; sin embargo, en los últimos años la República Popular China registra datos que son la envidia de sus países vecinos y su competencia.
En la actualidad, China es la cuarta economía en el mundo y ocupa el tercer lugar en movimiento comercial. Según datos del gobierno alemán, se espera que este año China supere a Alemania como primer exportador mundial. A pesar de ello, este país tiene ante sí una inmensa tarea: 800 millones de personas viven en zonas rurales y la mitad de ellas subsiste del campo. Sin embargo, la agricultura aporta tan solo $11 \%$ del PBI, porcentaje que sigue disminuyendo, mientras que la industria (49\%) y los servicios $(40 \%)$ continúan incrementándose.

Esta era de la globalización trae nuevos y diferentes desafíos respecto del trato comercial con China y cualquier otro país o cultura². Según el investigador especializado en dimensiones culturales G. Hofstede (s.f.), el índice de disparidad cultural que muestran los chinos

2. En este punto prefiero no ahondar sobre el término cultura, el cual resulta muy vasto si se aplican sus acepciones antropológicas, etnográficas u otras. 
es muy alto, inclusive teniendo en cuenta la gran cantidad de países con los que tienen fronteras.

China se ha abierto y está ingresando al mundo occidental con características propias y particulares, producto de su historia y actual situación socioeconómica, política y cultural. Las transformaciones y la expansión de los mercados chinos no tienen precedentes, tal como su apertura que la convierte en uno de los mayores y más interesantes mercados del futuro.

Nuestras relaciones con la cultura china, recordemos que ya en el año 2000 eran 4,25 millones (Rodríguez Pastor, 2000: 27) los peruanos descendientes de aquellos chinos llegados en los últimos 150 años al Perú (desde luego que en la actualidad esa cifra se ha incrementado), favorecen la posibilidad del Perú de encontrar mayor apertura sin que esto signifique que existan favoritismos infundados. Cada paso en falso que demos es una oportunidad que dejamos pasar para beneficio de la competencia y, pasada la oportunidad, no son útiles lamentaciones o justificaciones. La población de China es de aproximadamente $1300 \mathrm{mi}$ llones de personas ${ }^{3}$. Si se dice que $2 \%$ de la población de un país es superdotada con un coeficiente intelectual (IQ) por encima del promedio, esto significa que la cantidad de chinos superdotados es la misma que la población total del Perú. No se debe olvidar que hoy en día China representa uno de los mercados más grandes y difíciles en el mundo.

La cultura china no es igual a la de los migrantes chinos que vinieron al Perú. China es una potencia que busca expandir sus mercados y sus inversiones. Los empresarios chinos están altamente capacitados. Está en nosotros saber canalizar y negociar de manera inteligente esta oportunidad que se nos presenta, teniendo también en cuenta el grado de asimilación existente.

\section{Breve reseña histórica sobre los migrantes chinos al Perú}

Los primeros culíes (collies o colly), término que según la Enciclopedia Británica viene del vocablo koli o kuli,

3. Sin incluir Hong Kong, Macao ni Taiwán. aplicado por lo general a los trabajadores clasificados como inexpertos y distintos a los llamados artesanos (Rodríguez Pastor, 2000: 21), llegaron al Callao el 15 de octubre de 1849 (año en que se promulgó la Ley de Inmigración).

Entre los años 1849-1869 y 1870-1874 la cantidad de migrantes chinos fue de 45 a 50 mil en cada periodo (Rodríguez Pastor, 2000: 162). Ellos venían con un contrato que los obligaba a trabajar durante 8 años en todo tipo de trabajo. A partir de 1882 finalizaron los últimos contratos; sin embargo, fueron muy pocos aquellos que eligieron retornar a su país. Los nuevos migrantes no llegaron con contratos fijos, sino que vinieron de forma voluntaria y libre con la intención de crearse ellos mismos un porvenir. Desde sus inicios hasta la actualidad la migración china no se ha visto interrumpida.

Este es el más numeroso grupo social extranjero que se integró a nuestra sociedad. Hasta el año 2000 se calculaba que los descendientes de chinos eran entre 15 y $17 \%$ de la población peruana de 25 millones de habitantes. Lo que equivale a de 3,75 a 4,25 millones de peruanos que descienden de aquellos migrantes chinos llegados en los últimos 160 años al Perú (Rodríguez Pastor, 2000: 27).

Es de suponer que por lo menos la tercera parte de los culíes se relacionaron y formaron familia con mujeres lugareñas (en su mayoría de la costa) o con migrantes serranas. Inicialmente, y con un promedio de tres hijos por cada pareja binacional, se calcula en aproximadamente 90 mil los hijos de chinos con peruanas. Y, de acuerdo con la misma proporción de hijos por persona, los nietos solo de los culíes podrían haber sido cerca de 270 mil (Rodríguez Pastor, 2000: 224).

Los miles de decenas de chinos culíes llegados al Callao entre 1849 y 1874 fueron los indispensables trabajadores de las haciendas de caña de azúcar y algodón de la costa, también de la extracción de guano de las islas, la construcción de ferrocarriles y de otros centros laborales (Rodríguez Pastor, 2000:216).

Tras cumplir su contrato de ocho años, la mayoría prefirió dedicarse a la agricultura, el comercio, el 
transporte, servicios y oficios como cocina (implementando sus propias fondas), industrias y artes manuales, entre otros. Se concentraron en Lima y otras grandes ciudades del país en el área comercial, en la cual obtuvieron, gracias a su laboriosidad y precios sin competencia, gran acogida; asimismo, generaron importantes recursos económicos para los municipios, por el pago de impuestos en los lugares donde se instalaron.

Los chinos que llegaron después de 1874 constituyeron parejas mixtas y multiculturales. Aquellos de menor poder adquisitivo fueron absorbidos por las diferentes regiones del país (costa, sierra y selva) donde se instalaron. Por esta razón, en los sectores populares se originaron la gran mayoría de mezclas interétnicas al no poder los varones formar familia con sus pares debido a que las mujeres chinas inmigrantes eran muy pocas. Los hijos tuvieron una educación con doble tradición cultural, en la que predominó la peruana, ya que era el ambiente social que rodeaba a esas familias. Los más pudientes, o aquellos con ambos padres chinos, mantuvieron como hasta la actualidad sus costumbres originales.

A lo largo del tiempo, la cultura china ha tenido gran influencia en nuestro país. Gran cantidad de estudios y artículos nacionales e internacionales concluyen que la asimilación de la cultura china en el Perú ha sido un fenómeno irrepetible en otras sociedades y que en ningún otro lugar ha sido tan exitosa (Tesis de Zhou Yan: 2006). Este proceso, que en la actualidad cumple 160 años, ha dado como producto un amplio mestizaje racial y cultural. Son millones los peruanos que tienen sangre china, y lo ideal sería que los interesados se preocuparan por informarse acerca de la cultura china para estar en condiciones de entablar negocios de manera satisfactoria y no improvisada con comerciantes, inversionistas o empresarios chinos.

\section{Ejemplo práctico de «competencia intercultural» en una cita de negocios}

Este ejemplo 4 puede servir a cualquier persona que quiera tener contacto con integrantes de la cultura china, sea en el Perú o en el extranjero. Los interesados en

4. Adaptado del testimonio de un pequeño empresario chiclayano. entablar o mejorar su relación con la cultura china deben prestar atención a las recomendaciones dadas en el ejemplo práctico que se expone a continuación. Se trata de reconocer situaciones que se pueden presentar y saber responder y actuar de una manera que nos haga sentir cómodos y también nos beneficie y haga sentir bien a la otra parte. En otras palabras, salir airosos de situaciones ajenas a nuestro contexto cultural.

\begin{abstract}
«Me levanto de muy buen ánimo. He dormido bien y me preparo para comenzar el día. Tengo citas de negocios. Salgo de casa de mi hermano, tomo un taxi y en el camino voy pensando que soy una persona emprendedora y exitosa. Corren por mí mente ideas como: definitivamente mi producción no va a cubrir las necesidades de los mercados, los inversionistas van a estar deseosos de poder participar del crecimiento de mi empresa, quizá más de uno quiera asociarse conmigo, definitivamente todo está de mi lado, etcétera».
\end{abstract}

«He llegado con 10 minutos de anticipación a la primera cita, lo que significa que es posible que tenga alguna conversación extra. Uno nunca sabe, puede salir algo 'interesante.' Al ingresar al hotel diviso al señor Chang parado en el vestíbulo (lo reconozco porque he visto su fotografía en un catálogo): es un ejecutivo maduro, muy bien vestido y con buena presencia, a su lado está un joven. Estoy con el tiempo justo: tengo esta primera cita, luego un corto intervalo e, inmediatamente, el siguiente encuentro»

«Me voy acercando con paso firme y cuando estoy frente al señor Chang me presento, le doy la mano con la seguridad que me caracteriza, me inclino un poco y le digo que es un placer conocerlo, también saludo al joven amigablemente. Me encamino junto con ambos a un salón del hotel. Mi idea es hablar con calma acerca de futuros negocios. Nos sentamos y el mozo demora en acercarse, esto me causa fastidio, así que llamo al capitán de meseros y le digo que no es posible que los extranjeros se lleven una mala imagen del servicio y que por favor me atiendan eficientemente. Mis quejas son escuchadas, el capitán de meseros se disculpa y nos asigna un mozo solo para nuestro servicio. El señor Chang sonríe amistosamente, el joven también. Quiero saber qué ofertas concretas tiene para mí el señor Chang. Mi interlocutor me aclara que 'el señor Chang' es el joven que nos está acompañando. Me disculpo y continúo con mi exposición. Hablamos, le planteo mis inquietudes y desconfianza respecto de los contratos con nuevos clientes».

«El tiempo ha trascurrido muy rápido y la negociación ha sido lenta. Mi siguiente cita es en 10 minutos. Llamo al mozo y le pido la cuenta. Me excuso con mis interlocutores y les explico que por la demora en la atención se había perdido mucho tiempo y me están esperando para 
la siguiente cita. Les dejo mi tarjeta sobre la mesa. Estoy apurado. Ambos se paran y el señor Chang me entrega su tarjeta, la tomo y guardo en mi portafolio; le doy un abrazo, me despido amigablemente, le hago presente que ya todo está cancelado y que para cerrar el trato vaya a mi oficina y se contacte con mi gerente de ventas; que no se preocupe pues voy a dar instrucciones para que lo atiendan como se merece».

Algunos elementos propios de la competencia intercultural, referidos a actitudes, conocimientos, destrezas o habilidades, habrían evitado ciertos puntos negativos que impidieron una comunicación óptima entre ambas partes:

- Comprensión y conocimiento de la historia y la cultura. Quizás antes del encuentro debería haber reflexionado acerca de las tradiciones y las costumbres chinas. La cultura oriental es muy protocolar.

- Los «apretones» de manos. Estos no son usuales en la cultura china, cuando ocurren deben ser «suaves».

- La inclinación para saludar. Solo se hace una leve inclinación de la cabeza.

- Abrazos y besos. No se estilan, tampoco entre mujeres.

- Poco a poco se va ganando la confianza. Es posible que una conversación corta e interesante sea útil, pero definitivamente en «unos» minutos no se puede concretar absolutamente nada significativo.

- Prestigio, paciencia y arrogancia. Las llamadas de atención en público desprestigian a la otra persona y esto es mal visto por los chinos. Un poco de paciencia y comprensión no hubieran perjudicado a nadie.

- Reciprocidad y garantía en las relaciones. Expresar desconfianza es no estar abierto a una buena relación, casi se podría catalogar como una ofensa.

- El factor tiempo. Generalmente, con los chinos se acostumbra calcular entre 3 y 6 veces más de tiempo. En su planificación considere este elemento. Se espera de usted el tiempo necesario para hacer un negocio importante que tiene que perdurar en el tiempo. NO subestime jamás el tiempo que va a invertir en las negociaciones. El dicho «Time is of the essence» en China solo conlleva al FRACASO en las negociaciones.

- Las jerarquías. Desempeñan un papel muy importante. Esto significa que en el trato diario prevalecen las jerarquías, una regla clásica del confucionismo.

- Negociaciones. Lo fundamental, las decisiones, viene al final.

- Acerca de las tarjetas de visita. Estas se dan y reciben con ambas manos y con mucho respeto. Deben ser cogidas por las esquinas para no cubrir lo que está escrito y ser leídas con interés como muestra de respeto.

En realidad, se podrían hacer más críticas constructivas pero pienso que con estos aspectos es suficiente para mostrar el gran déficit que tenemos en competencias interculturales ${ }^{5}$.

\section{REFLEXIONES Y CONCLUSIONES}

La era de la globalización nos lleva a un conjunto de reflexiones no solo sobre el nivel nacional sino también sobre el internacional. Debemos estar conscientes de que somos una patria, una nación, un Estado, un país, una unidad, un Perú que tiene el gran reto de enfrentarse a los grandes desafíos de esta época. Tenemos que estar preparados para expandir nuestros mercados y recibir inversiones. Para ello es indispensable un clima nacional de paz y armonía.

Si bien la descentralización del Estado se percibe desde el punto de vista administrativo, se tienen que diseñar políticas coherentes, bien proyectadas y articuladas, para llevar a cabo una descentralización de la industria y la producción nacionales y de las futuras inversiones extranjeras.

5. Una persona me comentaba que algunos pisos de los hoteles en China tienen «baños occidentales». Quizá los arquitectos de un buen nivel de competencia intercultural deberían adecuar en el futuro algunos de nuestros hoteles con «baños orientales» para la gente de negocios o los turistas chinos u orientales. 
La educación peruana en las zonas rurales tiene que modificar sus estrategias desde los puntos de vista cuantitativo y cualitativo. Debe ser capaz de llegar en un menor plazo hasta las poblaciones más alejadas. En general, se deben redefinir los planes de estudio y las metas de la educación en zonas urbanas y rurales tanto en el nivel escolar como en el superior.

Definitivamente, como dice Tubino (2008: 181), debemos «interculturalizar el multiculturalismo» existente en el Perú desde el punto de vista conceptual y político. Tenemos que crear una conciencia nacional basada en las competencias interculturales que TODOS estemos dispuestos a aprender, respetar y aplicar. De ello va a depender en gran parte nuestra capacidad de contar con una fuerza laboral dispuesta a apostar para y por el futuro del Perú y su gente en TODO nuestro teritorio.

Se debe tener en cuenta que el declive de la formación del capital humano hace a las economías no competitivas, sea por su menor productividad o debido a su dependencia de la fuerza de trabajo calificada inmigrante. Asimismo: «Cuanto más se apoye una sociedad en la movilidad del capital y la inmigración para producir trabajo de conocimiento, menor será el papel del Estado» (Castells, 2003:348). Lo que significa ser un ciudadano de segunda o tercera categoría en el propio territorio.

La gente debe aprender a desplazarse por el interior del país con actitudes, conocimientos y habilidades propios de la competencia intercultural que debemos desarrollar con respecto a las diversas culturas existentes en nuestra patria. Debemos aprender a tener competencia intercultural no solo en el nivel internacional sino también en el nivel nacional. Se debe apreciar y respetar el medio en el que viven otras culturas en el Perú y encontrar y apoyar perspectivas dignas de trabajo para estas personas. El peruano es un trabajador y un profesional muy apreciado en el extranjero; sin em- bargo, estamos fallando en competencia intercultural en nuestro propio país.

Además, los empresarios deben comprender, apreciar y diferenciar los diversos tipos de cultura laboral existentes en nuestra realidad. Por ejemplo: no es lo mismo un trabajador minero que realiza labores a tajo abierto que otro que ingresa a un socavón. Si los gobiernos no aprovechan el potencial de sus ciudadanos, el país queda a la deriva y puede caer en manos del mejor postor, quien muchas veces viene del extranjero o está en el extranjero.

De acuerdo con las últimas estadísticas, las edades de $85,6 \%$ de los emigrantes fluctúan entre los 15 y los 44 años de edad. Otro dato indica que entre los años 1997 y 2006, 53,6\% fueron emigrantes mujeres (INEI, 2008). Lo que significa que gran parte de nuestro capital humano en edad óptima para trabajar está saliendo del país. Además, la tasa de natalidad en el Perú viene descendiendo desde hace varios años y la feminización de la migración hace que exista el riesgo potencial de que la fuerza laboral de nuestro país pueda llegar a descender notablemente, lo que influirá también sobre la producción.

Bruce comenta: «Paradójicamente, en la magnitud de nuestras dificultades de integración y funcionamiento radica tanto un desafío titánico como un campo de investigación de inigualable riqueza» (2007: 19).

¿Estamos los peruanos en capacidad de ponernos en el lugar del otro, crear y asumir nuevos patrones culturales para una mejor convivencia que sirva de ejemplo a las generaciones futuras en este histórico momento llamado era de la globalización? Uno de los mejores ejemplos de lo que es competencia intercultural lo tenemos aquí, en los migrantes chinos que llegaron al Perú hace 160 años. Personalmente, creo que la respuesta TIENE que ser afirmativa pues de lo contrario la historia nos hará ver la gran falta que cometimos en el pasado. 


\section{Referencias bibliográficas}

Aneas Álvarez, María. (2005, 25 de marzo).Competencia intercultural, concepto, efectos e implicaciones en el ejercicio de la ciudadanía. Revista lberoamericana de Educación (Organización de Estados Iberoamericanos para la Educación, la Ciencia y la Cultura (OEI), 35. <http:// www.aulaintercultural.org/IMG/pdf/920Aneas.pdf>. Consultado en octubre de 2007.

Bade, Klaus (ed.). (1996). Die multikulturelle Herausforderung. Menschen über Grenzen-Grenzen über Menschen. Munich: Beck.

Beck, Ulrich. (2004). Poder y contrapoder en la era global: la nueva economía política mundial. Barcelona: Paidós.

Beck, Ulrich. (2006). La Europa cosmopolita: sociedad y política en la segunda modernidad. Barcelona: Paidós.

Bourdieu, Pierre. (2002). Razones prácticas: sobre la teoría de la acción (3. ${ }^{a}$ ed.). Barcelona: Anagrama.

Bruce, Jorge. (2007). Nos habíamos choleado tanto: psicoanálisis y racismo. Lima: Universidad de San Martín de Porres.

Canetti, Elías. (1983). Masa y poder. Madrid: Alianza.

Castells, Manuel. (2003). La era de la información: economía, sociedad y cultura (2. a ed.). (Vol. 2: El poder de la identidad). Madrid: Alianza.

Chomsky, Noam. (2005). Sobre democracia y educación. Barcelona: Paidós.

Cómo hacer negocios con peruanos. (2004). <www.asilatin. com>.

Cotler, Julio. (2005). Clases, Estado y nación en el Perú. Lima: Instituto de Estudios Peruanos (IEP).

Durkheim, Emile. (1981). ¿Qué es un hecho social? (cap. 1). En Las reglas del método sociológico (pp. 29-39). Buenos Aires: La Pléyade.

Fischer, Verónica. (2003). Interkulturelle Kompetenz in der Fachwissenschaftlichern diskussion. Francfort: Dvv International.

Franco, Judith, Ilvento, María Celia, Renta, Ana Inés \& Segón, Ximena. (2008). Competencias interculturales en los programas universitarios de movilidad estudiantil. Salta:
Universidad Nacional de Salta.<http://www.mrioseco. net/descargas/mexico/INT001.pdf $>$. Consultado en marzo de 2009.

García, María Elena. (2008). Desafíos de la interculturalidad. Educación, desarrollo e identidades indígenas en el Perú. Lima: IEP.

Habermas, Jürgen. (1988). Erkenntnis und Interesse: mit einem neuen Nachwort. Francfort sobre el Meno: Suhrkamp.

Habermas, Jürgen. (1999). La inclusión del otro: estudios de teoría política. Barcelona: Paidós Ibérica.

Hofstede, Geert (s. f.) Cultural dimensions. <www.geerthofstede.com>. Consultado en noviembre de 2008.

La Porte, Teresa. (2006). La diplomacia americana: una apuesta por el recurso al poder blando. Análisis del Real Instituto Elcano (ARI) N. ${ }^{\circ}$ 103/2006. Madrid: Fundación Real Instituto Elcano. <http://www.realinstitutoelcano.org /analisis/1045.asp >.

Lausent-Herrera, Isabelle. (2000). Sociedades y templos chinos en el Perú. Lima: Fondo Editorial del Congreso del Perú.

Levitt, Theodore. (1983, mayo-junio). The globalization of markets. Harvard Business Review, 61 (3), 92-102.

Malik Liévano, Beatriz. (s. f.) Tema 17 (32 UUDD). Intervenciones para la adquisición de competencias interculturales. (Bloque 4. Intervenciones psicopedagógicas para el desarrollo de la persona). España: Universidad Nacional de Educación a Distancia (UNED). <www.uned.es >

Martuccelli, Danilo. (2007). Lecciones de sociología del individuo. Lima: Pontificia Universidad Católica del Perú (PUCP), Departamento de Ciencias Sociales.

Panfichi Huamán, Aldo (ed.). (2007). Magna: migraciones internacionales. Lima: Fondo Editorial de la PUCP.

Pareto, Vilfredo. (1980). Forma y equilibrio sociales: extracto del Tratado de Sociología General. Madrid: Alianza.

Perú. Instituto Nacional de Estadística e Informática (INEI). (2008). Encuesta Nacional Continua 2006 (ENCO): Perú: características de los migrantes internacionales, hogares de origen y receptores de remesas. Lima: INEI / Organización Internacional para las Migraciones (OIM). 
Programa Pro Descentralización (Prodes)-USAID Perú. (2008, octubre). Boletín O: Apuntes Descentralistas. Lima: Prodes-USAID.

Real Academia Española (RAE). (2001). Diccionario de la Len-

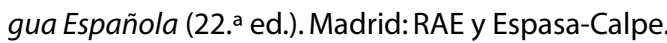

Rodríguez Pastor, Humberto. (2000). Herederos del Dragón: historia de la comunidad china en el Perú. Lima: Fondo Editorial del Congreso del Perú.

Rodríguez Pastor, Humberto. (2001). Hijos del Celeste Imperio en el Perú (1850-1900): migración, agricultura, mentalidad y explotación. Lima: Sur Casa de Estudios del Socialismo.

Santos Velasco, F. J. (2004). Desarrollo de la competencia intercultural en el alumnado universitario: una propuesta formativa para la gestión en empresas multiculturales. Tesis de Doctorado. Universidad de Barcelona. Barcelona.

Tesis de Zhou Yan, estudiante de la Universidad de Beijing, primer estudio académico de la integración china en el Perú desde la perspectiva china. (2006, sábado 10 de junio). El Comercio. <www.elcomercioperu.com>.

Tubino, Fidel. (2008). Interculturalizando el multiculturalismo. En Bibliotheque de la Mediterranée (pp.181-194).
Barcelona: Universidad de Barcelona. <www.cidob. org/es/content/download/2859/.../08_tubino_cast. pdf $>$. Consultado en junio de 2009.

Villoro, L. (1998). Estado y pluralidad de culturas. México, D. F.: Paidós.

Zülch, Martin. (2004). «Mc World» oder «Multikulti»? Interkulturelle Kompetenz im Zeitalter der Globalisierung. En Gunther Vedder (ed.). Diversity Management und Interkuturalität (pp. 3-78). Mering, Alemania: Rainer Hampp.

\section{Páginas de Internet}

Hofstede, Geert. <http://www.intercultural-network.de/ einfuehrung/kulturelle_dimensionen.shtml>. Consultado en diciembre de 2007.

<http://www.12manage.com/methods_hofstede_es.html>. Consultado en junio de 2009.

Internationale Diplomatenausbildung. <www.auswaertigesamt.de>.

GTZ. <www.gtz.de> 